\title{
NEURO-OPHTHALMIC AND CLINICAL CHARACTERISTICS OF BRAIN TUMOURS IN A TERTIARY HOSPITAL IN GHANA
}

\author{
N.N TAGOE ${ }^{1}$, V. A. ESSUMAN ${ }^{2}$, G. FORDJUOR ${ }^{2,}$ J. AKPALU $^{3}$, P. BANKAH ${ }^{4}$ and T. NDANU ${ }^{5}$ \\ ${ }^{1}$ Ophthalmology Unit, Department of Surgery, Korle-Bu Teaching Hospital, Accra, Ghana, ${ }^{2}$ Ophthalmology \\ Unit, Department of Surgery, University of Ghana Medical School, College of Health Sciences, Korle-Bu \\ Teaching Hospital, Accra, Ghana, ${ }^{3}$ Endocrine Unit, Department of Medicine, University of Ghana Medical \\ School, College of Health Sciences, University of Ghana Medical School, Accra, Ghana, ${ }^{4}$ Neurosurgical Unit, \\ Department of Surgery, Korle-Bu Teaching Hospital, Accra, Ghana, ${ }^{5}$ University of Ghana Dental School, \\ College of Health Sciences, Korle-Bu Teaching Hospital, Accra, Ghana
}

DOI: http://dx.doi.org/10.4314/gmj.v49i3.9

Corresponding author: Dr. Naa Naamuah Tagoe

Conflict of Interest: None declared

\section{SUMMARY}

Background: Anecdotally, increasing number of patients are seen at Korle Bu Teaching Hospital (KBTH) with brain tumour. Neuro-ophthalmic symptoms and signs may help in timely diagnosis and intervention.

Objective: To evaluate the neuro-ophthalmic and clinical characteristics of brain tumour in patients presenting at a tertiary hospital in Ghana.

Study design: A prospective case series involving 36 consecutive patients newly diagnosed with brain tumour from November 2010 to October 2011, at the Ophthalmology, Neurosurgery and Endocrine units of KBTH, Ghana. All patients had clinical diagnosis of brain tumour with confirmation by computerized tomography (CT) or magnetic resonance imaging (MRI). Thirteen patients had histological confirmation of diagnosis.

Outcome measures: Presenting Visual acuity, Colour vision, Visual fields and Cranial nerve deficits.

Results: Data of 36 patients were analyzed. Ages ranged from 3 to 69years, mean (SD) $42.56( \pm 16.6$ years). Twenty-six (72\%) were females. Tumours included pituitary adenoma $(20,55.5 \%)$, meningioma(10,27.8\%), choroid plexus tumour(1,2.8\%), medulloblastoma $(1,2.8 \%)$,craniopharyngioma( $1,2.8 \%)$, haemangioblastoma(1,2.8\%), thalamic tumour(1,2.8\%) and haemangioma $(1,2.8 \%)$. Histologically confirmed tumours included pituitary adenoma $(9,69.2 \%)$, meningioma $(3,23.1 \%)$, craniopharyngioma $(1,7.7 \%)$. One patient had both a pituitary adenoma and meningioma. Blurred vision $(30,83.3 \%)$, headache $(28,77.8 \%)$ and photophobia $(13,36.1 \%)$ were predominant symptoms. Commonest neuro-ophthalmic signs were impaired colour vision (62 eyes, 88.6\%), optic atrophy (26, $74.3 \%$ ), unilateral or bitemporal hemianopia (15, $41.5 \%)$ and relative afferent pupillary defect (12, $34.3 \%)$. Seven (19.4\%) patients were visually impaired
E-mail: naanaamuahtagoe@gmail.com

and nine (25\%) blind. Thirty-three of 72(45.8\%) eyes had monocular blindness.

Conclusions: Common neuro-ophthalmic characteristics were blurred vision, headache, impaired colour vision, optic atrophy, and relative afferent pupillary defect (RAPD). Significant numbers of patients were blind or visually impaired at presentation.

Keywords: Brain tumour, neuro-ophthalmic characteristics, visual impairment, blindness, optic atrophy

\section{INTRODUCTION}

Primary intracranial tumours are a leading cause of morbidity and mortality in patients with neurological disease. ${ }^{1,2}$ Clinical features are caused by mass effect, irritation raised intracranial pressure or influence of hormones. ${ }^{2}$ The visual pathway and ocular nerves are not exempt from these effects. ${ }^{1,2,3}$

Neuro-ophthalmic manifestations may help diagnose tumours since the ophthalmologist may be the first point of call for patients with this tumours. ${ }^{1,45}$ Anecdotally, increasing number of patients are seen at Korle $\mathrm{Bu}$ Teaching Hospital (KBTH) with brain tumours. This study purposed to determine the neuro-ophthalmic and clinical features of intracranial tumour presenting at $\mathrm{KBTH}$

\section{METHODS}

A prospective case series involving 36 consecutive patients newly diagnosed with brain tumours seen from November 2010 to October 2011 at the KBTH, Accra, Ghana were studied. Ethical approval was obtained from the Ethical and Protocol Review Committee of the University of Ghana Medical School. Patients and carers who did not consent to participation were excluded from the study. 
All patients had clinical diagnosis of brain tumour with confirmation by either CT or MRI. Some patients had in addition, histological confirmation of diagnosis.

Demographic (age, sex, community of residence, history of symptoms), clinical (ophthalmic, endocrine, neurologic,) and histopathological data were recorded using a predesigned questionnaire.

\section{Ophthalmic evaluation}

This included visual acuity (VA) tested using appropriate test type for age: fixation methods and/or Cardiff cards for preverbal children $(\leq 2$ years) matching tests such as Animal Snellen's and Sheridan Gardner charts for pre-schoolers (3- 5 years) Snellen's charts (for both literate and illiterate) for children over 5 years and adults. For patients who were unable to see the letters at the closest test distance, the following test sequence was used: count fingers (CF) at $1 \mathrm{~m}$, hand movement (HM) at $1 \mathrm{~m}$, light perception (LP) and no light perception (NLP).

Best corrected Visual Acuity with spectacles (BCVA )was recorded using WHO categories of visual impairment adapted from the International Classification of Diseases (9th revision, 1975), visual status was graded as:

(a) 'Blind' when visual acuity (VA) was $<3 / 60$

(b) 'Impaired' when VA was $<6 / 18-3 / 60$

(c) 'Normal' when VA was 6/6-6/18.

Colour vision was tested using Ishihara Colour Vision Charts (38 Plate Edition 1994). External eye examinations included careful evaluation for proptosis using Hertel's exophthalmometer (G.Rodenstock Instrument; Munchen Hamburg, Germany) as well as assessment of ocular movements, diplopia and nystagmus. Anterior segment assessment included slit lamp examination using (Topcon ATE-600 2004, Japan), pupil reaction to light and relative afferent pupillary defect.

Fundus examination was done using biomicroscopy with a +90D lens, indirect ophthalmoscope with +20D/ $+28 \mathrm{D}$ lenses and direct ophthalmoscope through dilated pupils (using tropicamide $1 \%$, and or cyclopentolate eye drops $1 \%$ with phenylephrine $2.5 \%$ eye drops). Visual field was assessed using a Humphrey visual field analyser (SITA,Carl Zeiss Meditec; Dublin CA.USA, 2005). Assessment of the size of the tumour was done radiologically using Computerised Tomography scan (CT scan) Hitachi Eclos -2009 or Magnetic resonance imaging (MRI) Hitachi Airis elite (OPEN).

\section{Endocrine evaluation:}

This included clinical examination of patients by the endocrinologist and assessment of anterior pituitary hormones namely luteinising hormone(LH), follicle stimulating hormone(FSH), 9am serum cortisol, prolactin (PRL), triiodothyronine(free T3), thyroxin(free T4), and thyroid stimulating hormone(TSH).

\section{Neurosurgical evaluation:}

Neurosurgical evaluation by neurosurgeons involved history and examination of the nervous system. The mental state, cranial nerves, coordination, motor and sensory examinations were performed for each patient.

\section{Outcome measures}

Outcome measures studied included presenting Visual acuity, Colour vision, Visual fields and Cranial nerve deficits.

\section{Statistical Data Analysis}

Data was captured using Microsoft Access and analysed using Statistical Package for Social Scientists (SPSS) Version 16.0. Continuous numeric data were summarized as Mean and Standard deviation (SD) and categorical data as percentages (\%). Results were presented as frequencies, tables and charts.

To prove significant outcomes, $t$-test was used to compare mean levels of visual acuity between right and left eyes. Mann-Whitney Test was used for establishing significant association between, duration before presentation and, visual acuity, optic atrophy and RAPD. Correlation was used to assess linear relationship between tumour location and optic atrophy.

Chi-squared was used to compare proportions, at 0.05 significant levels. Logistic regression analysis was used to establish significant association between visual acuity and tumour type and size.

\section{RESULTS}

Data on 36 patients were analyzed. Thirty three $(91.7 \%)$ were adults and three $(8.3 \%)$ children. Ages ranged from 3 to 69 years (mean/SD 42.6 years \pm 16.6 ) with median age of $43.5 y$ ears. Twenty-six $(72 \%)$ were females. The duration of symptoms before presentation ranged from one to eighty-four months with mean of 8.7 and a median duration of 4.5 months.

\section{Pattern of referral}

Greater proportions $(14,38.9 \%)$ of patients were referred by Neurosurgeons at Korle Bu Teaching Hospital $(\mathrm{KBTH})$ followed by peripheral general hospitals (12, 33.2\%). 
Table 1 Pattern of referral to eye clinic

\begin{tabular}{|l|l|}
\hline Source of Referral & $\begin{array}{l}\text { Number of } \\
\text { patients (\%) }\end{array}$ \\
\hline Neurosurgeon & $14(38.9)$ \\
\hline Peripheral general hospitals & $12(33.2)$ \\
\hline Endocrinologist & $4(11.1)$ \\
\hline Gynaecologist & $2(5.6)$ \\
\hline Psychiatrist & $2(5.6)$ \\
\hline Private eye clinic & $2(5.6)$ \\
\hline Total & $36(100)$ \\
\hline
\end{tabular}

\section{General neurologic presentation}

Headache $(28,77.8 \%)$ was the commonest general symptom reported. 'Others' $(7,19.4 \%)$ in Table 2 included right hemiparesis (2), memory loss(1), hoarseness of voice(1), static attacks(1), lid retraction(1) and left lower limb paresis(1).

Table 2 General Symptoms and signs associated with brain tumour

\begin{tabular}{|l|l|l|l|}
\hline Symptom & $\begin{array}{l}\text { Number } \\
(\%)\end{array}$ & Symptom & $\begin{array}{l}\text { Number } \\
(\%)\end{array}$ \\
\hline Headache & $28(77.8)$ & $\begin{array}{l}\text { Irregular } \\
\text { menses }\end{array}$ & $5(13.9)$ \\
\hline $\begin{array}{l}\text { Behavioural } \\
\text { change }\end{array}$ & $7(19.4)$ & Seizure & $4(11.1)$ \\
\hline Anosmia & $7(19.4)$ & Tinnitus & $4(11.1)$ \\
\hline Amenorrhoea & $7(19.4)$ & Motor palsy & $4(11.1)$ \\
\hline Other & $7(19.4)$ & Nausea & $3(8.3)$ \\
\hline Vomiting & $5(13.9)$ & Ataxia & $2(5.6)$ \\
\hline Galactorrhoea & $5(13.9)$ & $\begin{array}{l}\text { Neck swell- } \\
\text { ing }\end{array}$ & $1(2.9)$ \\
\hline
\end{tabular}

Two (2) patients had been detained at a psychiatry hospital for five and three years respectively for abnormal behaviour with an impaired sensorium or amnesia respectively.

\section{General ocular signs and symptoms}

The commonest ocular symptom was visual blur (30, $83.3 \%)$. Other common complaints were photophobia $(11,31.4 \%)$ and ocular pain $(11,31.4 \%)$.

All four patients with proptosis had meningioma. Two of these patients died, one after surgery and the other before scheduled surgery. Cause of death was unconfirmed because they were lost to follow up.

\section{Neuro-ophthalmic signs}

Impaired colour vision was the commonest neuro ophthalmic sign in this study. Sixty-two of 70(88.6\%) eyes had impaired colour vision. There was however no significant association between duration before presentation and degree of colour vision in the right $(p=0.271)$ or left $(p=0.369)$ eyes. Two patients did not have colour vision recorded, one of these had impaired sensorium from a massive frontal lobe tumour and the other was a three year old child who could not read the colour plates.

Other neuro-ophthalmic signs were optic atrophy (26, $74.3 \%)$, RAPD $(12,34.3 \%)$ and swollen optic discs (9, $25 \%$ ) (Table3) There was no significant association between duration before presentation and either RAPD $(p=0.220)$ or optic atrophy $(p=0.118)$ in either eye.

Table 3 Ocular and neuro-ophthalmic symptoms and signs

\begin{tabular}{|l|l|l|l|l|}
\hline $\begin{array}{l}\text { Ocular } \\
\text { Symptom }\end{array}$ & $\begin{array}{l}\text { Right } \\
\text { Eye } \\
\text { N }(\%)\end{array}$ & $\begin{array}{l}\text { Left } \\
\text { Eye } \\
\text { N }(\%)\end{array}$ & $\begin{array}{l}\text { Both } \\
\text { Eyes } \\
\text { N }(\%)\end{array}$ & $\begin{array}{l}\text { Total N } \\
(\%)\end{array}$ \\
\hline Visual blur & $5(13.9$ & $4(11.1)$ & $21(58.3)$ & $30(83.3)$ \\
\hline Ocular pain & $3(8.3)$ & $6(16.7)$ & $2(5.6)$ & $11(30.6)$ \\
\hline Red Eye & $0(0)$ & $1(2.8)$ & $0(0.0)$ & $1(2.9)$ \\
\hline Photophobia & $1(2.9)$ & $1(2.8)$ & $11(30.6)$ & $13(36.1)$ \\
\hline NEUROOPHTHALMIC & & & & \\
\hline Proptosis & $4(11.1)$ & $0(0.0)$ & $0(0.0)$ & $4(11.1)$ \\
\hline Diplopia & $0(0.0)$ & $0(0.0)$ & $1(2.9)$ & $1(2.9)$ \\
\hline Optic disc swelling & $2(5.6)$ & $1(2.8)$ & $6(16.7)$ & $9(25.0)$ \\
\hline Optic disc atrophy & $5(13.9)$ & $2(5.8)$ & $19(52.8)$ & $26(74.3)$ \\
\hline Normal optic disc & $1(2.9)$ & $0(0.0)$ & $3(8.3)$ & $4(11.4)$ \\
\hline Ptosis & $2(5.7)$ & $0(0.0)$ & $0(0.0)$ & $2 .(5.7)$ \\
\hline RAPD & $5(14.3)$ & $7(20)$ & $0(0.0)$ & $12(34.3)$ \\
\hline Ocular nerve palsy & $2(5.7)$ & $0(0.0)$ & $5(14.3)$ & $7(20.0)$ \\
\hline Nystagmus & $0(0.0)$ & $0(\mid 0.0)$ & $1(2.9)$ & $1(2.9)$ \\
\hline Strabismus & $0(0.0)$ & $0(0.0)$ & $1(2.9)$ & $1(2.9)$ \\
\hline Shunt vessels on disc & $1(2.9)$ & $0(0.0)$ & $0(0.0)$ & $1(2.9)$ \\
\hline
\end{tabular}

Table 4 Imaging diagnosis and visual field type

\begin{tabular}{|l|l|l|l|}
\hline Tumour type & $\mathbf{N}(\mathbf{\%})$ & Visual field type & $\mathbf{N}(\mathbf{\%})$ \\
\hline Meningioma & $10(27.8)$ & $\begin{array}{l}\text { Uni/bitemporal } \\
\text { hemianopia }\end{array}$ & $15(45.5)$ \\
\hline Pituitary adenoma & $20(55.5)$ & Normal & \\
\hline $\begin{array}{l}\text { Choroid plexus tu- } \\
\text { mour }\end{array}$ & $1(2.8)$ & Total field loss & $4(12.1)$ \\
\hline Medulloblastoma & $1(2.8)$ & $\begin{array}{l}\text { Superior quadran- } \\
\text { tanopia }\end{array}$ & $2(6.1)$ \\
\hline Haemangioblastoma & $1(2.8)$ & $\begin{array}{l}\text { Junctional scoto- } \\
\text { ma }\end{array}$ & $2(6.1)$ \\
\hline Craniopharyngioma & $1(2.8)$ & $\begin{array}{l}\text { Homonymous } \\
\text { hemianopia }\end{array}$ & $1(3.0)$ \\
\hline Thalamic tumour & $1(2.8)$ & Inferior altitudinal & $1(3.0)$ \\
\hline Haemangioma & $1(2.8)$ & Inferior arcuate & $1(3.0)$ \\
\hline Total & $36(100)$ & $\begin{array}{l}\text { Non specific } \\
\text { visual field }\end{array}$ & $1(3.0)$ \\
\hline & $\begin{array}{l}\text { Total number with } \\
\text { visual fields done }\end{array}$ & $33(100)$ \\
\hline
\end{tabular}

Blindness and visual impairment at presentation Nine $(25 \%)$ patients were bilaterally blind. Monocular blindness occurred in 33 of $72(45.8 \%)$ eyes. Most eyes $(45,62.5 \%)$ examined were either visually impaired or blind. 
There was no significant difference in blindness or visual impairment between right and left eyes $(p=0.726)$. There was also no significant association found between time before presentation and visual acuity $(\mathrm{p}=0.288)$.

The commonest visual field defects detected in this series, were unilateral or bitemporal hemianopia (15, 41.5\%).Other visual fields are shown in Table 4.

\section{Tumour location and type}

Majority $(28,77.8 \%)$ of the tumours were parasella in location followed by the temporo-parietal part of the brain $(4,11 \%)$. There was no significant association found between tumour location and optic atrophy $(\mathrm{p}=0.505)$ or visual acuity $(\mathrm{p}=0.257)$. Pituitary adenoma $(20,55.5 \%)$ and meningioma $(10,27.8 \%)$ were the commonest tumours in this study. (Table 4) All ten cases of meningioma were females. Tumours in the three children in this study were craniopharyngioma, medulloblastoma and choroid plexus tumour however, only the craniopharyngioma was histologically confirmed.

\section{Hormonal status}

Fourteen (48.3\%) of 29 patients who had anterior pituitary homone analysis had high prolactin levels above the normal value. All these patients had pituitary adenomas.

\section{DISCUSSION}

Intracranial tumours are second only to stroke as the leading cause of death from neurological disease. ${ }^{1}$ In developing countries severe to complete visual loss from optic atrophy has been described due to late presentation. ${ }^{2,4}$ Ophthalmic signs and symptoms occur as an initial presentation in up to fifty percent of patients diagnosed with primary brain tumours in adults $^{2,4,5,6}$ and up to 39 to $43 \%$ in children. ${ }^{7}$ Children however present with less specific symptoms than adults. ${ }^{7}$

In this series $30(83.3 \%)$ patients presented with blurred vision. This corroborates other studies which reported reduced vision. ${ }^{1,3,8}$ Pituitary adenoma and meningioma were the most common tumours in this series as was the case in some series, ${ }^{3,8}$ but this is in contrast with other studies which reported meningioma as the commonest. ${ }^{1,2,4,9,10,11}$ This difference in our series may be due to diagnosis of the patients confirmed mostly by neuroimaging studies rather than histologically.

Only 13 of our patients had histological confirmation of diagnosis because they could not afford surgery. The shorter duration of recruitment in this study in compar- ison with other series with longer duration in recruitment ${ }^{1,2,3,4}$ may also be a contributory factor. Most tumours in this series were located in the parasella and temporo-parietal part of the brain as was the case in a Kenyan series. ${ }^{4}$

The male: female ratio was 1: 2.6 which is similar to findings from other studies ${ }^{1,12}$ However, it is in contrast with observations from Nigeria, ${ }^{2,13}$ which shares similar geographic and demographic features in the West African Sub-region. The greater number of females in this study may be due to general female preponderance of meningiomas and pituitary adenomas. $1,3,8,13,14,15$ The disparity in sex distribution between this study and the Nigerian studies may also be attributed to the bulk $(83.3 \%)$ of tumours in this study being meningiomas and pituitary adenomas whereas this group of tumours constituted $52.1 \%$ and $39.8 \%$ in Onapoya's ${ }^{2}$ and Idowus's series ${ }^{13}$ respectively.

All the patients with meningioma in this series were females which are similar to findings in other series which report a female preponderance for meningiomas. ${ }^{2,13,15}$ This mean age of presentation in this study is similar to a study in Nigeria ${ }^{13}$ but higher than other studies. ${ }^{1,2}$

A greater number of patients were referred from the neurosurgeon as opposed to Onapoya's series in which a similar percentage of $40.9 \%$ were from private hospitals. ${ }^{2}$ The greater referral from the neurosurgeon in our series may be due to the neurosurgeons routine of referring patients with brain tumours for ophthalmic evaluation before surgery. The primary source of referral may have been from other hospitals and clinics and the neurosurgeon may have been the secondary referral source.

Two patients were referred from the psychiatrist at advanced stages having been kept there for three to five years before diagnosis. These patients got referred to the ophthalmologist only when they complained of poor vision. Psychiatric symptoms as was found in these two patients is not uncommon and indeed, symptoms like depression, hallucination and personality changes in patients with intracranial tumours are well documented. ${ }^{10,12}$

This study shares a variability in duration of symptoms before presentation with some series ${ }^{2,3,8}$ but differs from them in not having any presentation within days. The most common presentations were blurred vision, headache and photophobia.

Blurred vision $30(83.3 \%)$ as seen in this study is well documented in many other series of patients studied with brain tumours. $1,2,3,4,7,8$ 
Majority $(28,77.8 \%)$ of our patients reported headache at presentation. This is a recognized symptom manifest in $43 \%$ to $99 \%$ of patients with brain tumour. ${ }^{1,4,10,12,16,17,18}$ Monocular blindness 33 of $72(45.8 \%)$ eyes was commoner than bilateral blindness as was the case in one larger study. ${ }^{8}$ Of the 72 eyes examined in this series majority $45(62.5 \%)$ were either visually impaired or blind. This is similar to a study in Kenya ${ }^{4}$ but not others. ${ }^{2,3}$ The authors attribute the higher number of blind or visual impaired to primary optic atrophy as a result of compression from pituitary adenoma and meningioma which were the common tumours seen in this study as well as to late presentation of patients. Late presentation in this study is similar to what pertains in other studies in developing countries. $^{2,4}$ Visual loss in pituitary adenoma and meningioma turns to be insidious. ${ }^{3,16}$ Subtle visual deficits especially when unilateral are often underestimated and may be attributed to aging or stress and imaging performed only when damage is severe. ${ }^{19}$

The number of bilaterally blind in our series was however lower than that of Kilthisak's larger series in Thailand. ${ }^{3}$ Tumours in the sella region are known to cause severe visual loss due to their close proximity to vital neurovascular structures particularly the optic chiasm $^{20}$ This difference between the two studies is difficult to explain ,but may be due to small sample sizes. Further studies may be necessary. Post-operative improvement in vision is disappointing in patients with severe visual impairment associated with optic atrophy. ${ }^{20}$ This however, is not unexpected as the optic nerve does not regenerate. Limited resources for neuroimaging and surgery are of great concern since in Ghana, initiation of appropriate and early therapy further delay the burden of severe visual impairment and blindness from these tumours. This study however, did not find any significant association between tumour site and visual acuity $(\mathrm{p}=0.257)$.

This differs from a study in Kenya which found a significant correlation between tumours compressing the anterior visual pathway and degree of visual impairment. ${ }^{4}$ This difference is difficult to explain and further studies in a larger series over a longer period may be necessary. No significant association between time before presentation and visual acuity was found in this study $(p=0.288)$. This is in contrast to a study from Nigeria. ${ }^{21}$ This may be due to large variability in time before presentation in a smaller sample of patients in this series and also that the Nigerian study was limited to meningioma's.

The percentage of patients with optic atrophy (74.3\%) is similar to a series in Saudi Arabia ${ }^{20}$ but higher than others. $^{1,3,4}$ This higher percentage of optic atrophy may be explained by late presentation of patients in this study as well as the fact that this study, being prospective, had the advantage of thorough review of optic disc as opposed to the others which were retrospective studies in which case notes were reviewed and as such optic atrophy may have been missed or not documented.

There was however no significant association between duration before presentation and optic atrophy in either eye $(p=0.118)$. In developing countries profound to complete visual loss from optic atrophy has been described due to late presentation. ${ }^{2,4}$ This disparity of association between duration before presentation and optic atrophy in our study is difficult to explain. Further studies may be needed to explain this. Relative afferent pupillary defect (RAPD) is an important sign in patients with optic neuropathy and may be an early sign of unilateral optic nerve compression in patients with brain tumour or asymmetric growth of a parasella brain tumour. RAPD was elicited in $34.3 \%$ of our patients. This was lower than that seen in other larger series $^{1,3,4}$

The lower percentage of patients with RAPD in our series can be explained by the higher percentage of bilateral optic atrophy due to late presentation and to most tumours in this series being parasella in location and thus compressing the optic chiasm. There was no significant association between duration before presentation and RAPD $(p=0.220)$. This may be due to the wide range in duration of symptoms before presentation of between one month to seven years.

Colour vision defect in this series was higher than that seen in Marco S. et al's series. ${ }^{4}$ in which $63 \%$ of the cases had colour vision defect. The higher number of eyes with colour vision impairment may be due to most cases in this series being either monocularly or bilaterally blind or visually impaired at presentation and as such were unable to recognize the colour plates shown them.

Unilateral or bitemporal hemianopia was the common visual field defect in $45.5 \%$ of the 33 patients who had visual field test performed in this study. This is the typical field seen in patients with pituitary adenomas with compression from below. ${ }^{3}$ Thus it is not unexpected since a high percentage $(77.8 \%)$ of patients with parasella tumour were seen in this series. Unilateral blurred vision and hemianopia seen in some patients in this study corroborates a study in Thailand of a similar sample size of 40 patients. $^{8}$ 
Prolactin was the highest (48.3\% of 29) anterior pituitary hormone secreted by patients with pituitary adenoma in this study. This is similar to a Finnish study of hormones secreted by pituitary adenomas. ${ }^{14}$

\section{Strengths and limitations}

The main strengths of this study are its prospective nature and it being the first study to describe the neuroophthalmic and clinical characteristics of brain tumours in this population. However, the lack of histological confirmation of diagnosis in some patients and the small numbers studied were recognized limitations.

\section{CONCLUSION}

Pituitary adenoma and meningioma are the common intracranial tumours seen in Ghana. Though blurred vision and headache are common early symptoms, diagnosis is not made till very late due to late presentation. Colour vision impairment, optic atrophy and relative afferent pupillary defect were the commonest signs. Most of these patients presented with monocular or binocular blindness or visual impairment due to late presentation. Education of the public as well as physicians to pick up early signs and symptoms of brain tumours is important to ensure timely diagnosis and management.

\section{ACKNOWLEDGEMENT}

We acknowledge the contributions of Benjamin Abaidoo the senior research assistant, and nurses of the neuro ophthalmologic clinic, Ophthalmology Unit, Korle-Bu Teaching Hospital, as well as all resident ophthalmologists who helped with filling of the questionnaires.

\section{REFERENCES}

1. Masaya-anon P, Lorpattanakasem J.Intracranial tumours affecting the visual system: 5 year review in Prasat neurological Instititute. $J$ Med Assoc Thai. 2008;91(4):515-9

2. Onakpoya OH,Komolafe EO, Akintomide F, Ajite K, Komolafe MA, Adeolu AA, Olateju SO, Adeoye AO, Adegbehingbe B .Ophthalmic manifestations in patients with intracranial tumours. Afr. J. Neurol. Sci. 2009; 28(1):55-60.

3. Kitthisak K, Ployprasith C. Ocular Manifestations of Suprasellar Tumours. J Med Assoc Thai. 2008; 91 (5):711-5

4. Marco S, Karimurio J, Kariuki M, Lubanga P. Visual loss and Ocular involvement in adult patients with intracranial neoplasms in Kenyatta National Hospital, Nairobi, Kenya. East Afr J of Ophthalmol.2007; 13(1):15-20.
5. Kennedy HB and Smith RJ. Eye signs in craniopharyngioma. Br J Ophthalmol. 1975;59(12):68995

6. Schaefer U, Helmut W, Hart W, Clinical Neuro ophthalmology, a practical guide. 2nd edition, Tubengen: Springer, 2007 Feb.172, 176p.

7. Wilne SH, Ferris RC, Nathwani A, Kennedy CR. The presenting features of brain tumours a review of 200 cases. Arch Dis Child 2006; 91(6):502-6.

8. Aui-aree N, Phruanchroen C, Oearsakul T, Hirunpat S, Sangthong R. Three years' experience of suprasellar tumors in neuro-ophthalmology clinic. Med Assoc Thai. 2010; 93(7):818-23.

9. Kuratsu J, Ushio Y. Epidemiological study of primary intracranial tumours: a regional survey in Kumamoto Prefecture in the southern part of Japan. J Neurosurg 1996; 84(6):946-50.

10. Igun GO. Diagnosis and management of brain tumours at Jos University Teaching Hospital, Nigeria. East Afr Med J.2001; 78(3):148-151.

11. Nomura K. Present status of brain tumour statistics in Japan, Int J Clin Oncol.2000;5: 355-360

12. Ramesh K. Gupta, Rajeev K. Benign brain tumours and psychiatric morbidity: a 5-year retrospective data analysis. Aust N Z J Psychiatry. 2004 ;38(5):316-9

13. Idowu O, Akang E, Malomo A. Symptomatic primary intracranial neoplasms in Nigeria, West Africa. J Neurol Sci [Turk] 2007;24(3):212-8

14. Raappana A, Koivukangas J, Ebeling T, Pirila T. Incidence of Pituitary Adenomas in Northern Finland in 1992-2007. J Clin Endocrinol Metab. 2010; 95(9):4268-4275.

15. Das A, Chapman CA,Yap WM.Histological subtypes of symptomatic central nervous system tumours in Singapore. J Neurol Neurosurg Psychiatry 2000;68(3):372-4

16. Jen SL, Lee LS. Suprasellar meningiomas: analysis of 32 cases. Zhonghua Yi Xue Za Zhi Taipei 1997; 59(1):7-14.

17. Andrews NB. 'Brain tumour problems in Ghana', GhanaDot.com Sept 02 2009.web Oct 2009.

18. DeAngelis LM.Brain tumours. $N$ Engl J Med 2001;344(2):114-23

19. Müller-Forell W. Intracranial pathology of the visual pathway. Eur J Radiol 2004; 49(2) 143-178

20. Ashraf J, Imad K, Bengt R, Edir S,Suprasellar meningioma and blindness: a unique experience in Saudi Arabia, Surg Neurol. 1996; 45(4):320-3.

21. Odebode TO, Akang EE, Shokunbi MT, Malamo AO, Ogunseyinde AO. Factors influencing visual and clinical outcome in Nigerian patients with cranial meningioma. J Clin Neurosci. 2006 ;13(6):649-54 